\title{
Diffusion of Chromium and Palladium in $\beta$-Titanium
}

\author{
Sung-Yul Lee*, Yoshiaki Iijima** and Ken-ichi Hirano**
}

\begin{abstract}
Interdiffusion coefficients in the $\beta$ phase of $\mathrm{Ti}-\mathrm{Cr}$ and $\mathrm{Ti}-\mathrm{Pd}$ alloys have been determined by Matano's method in the temperature range between 1173 and $1823 \mathrm{~K}$ with (pure Ti)-(Ti-4.62 at $\% \mathrm{Cr}$ alloy) and (pure Ti)-(Ti-1.84 at\% $\mathrm{Pd}$ alloy) couples. The impurity diffusion coefficients of $\mathrm{Cr}$ and $\mathrm{Pd}$ in $\beta$-Ti have been determined by extrapolating concentration dependence of the interdiffusion coefficient to the infinite dilution of solute, and the following results have been obtained. In the whole temperature range, the diffusion coefficient of $\mathrm{Cr}, D_{\mathrm{Cr}}$, in $\beta$-Ti is about twice as large as the self-diffusion coefficient in $\beta$-Ti, $D_{\mathrm{T}}^{*}$. The magnitude of diffusion coefficient of $\mathrm{Pd}, D_{\mathrm{Pd}}$, in $\beta$-Ti lies in the range between $D_{\mathrm{Cr}}$ and $D_{\mathrm{Ti}}^{*}$, that is, at higher temperatures $D_{\mathrm{Pd}}$ is nearly of the same magnitude as $D_{\mathrm{Cr}}$ and at lower temperatures it is nearly equal to $D_{\mathrm{Ti}}^{*}$. Both the Arrhenius plots of $D_{\mathrm{Cr}}$ and $D_{\mathrm{Pd}}$ indicate an upward curvature showing the behavior of so-called anomalous diffusion in b.c.c. metals, but the curvature of $D_{\mathrm{Cr}}$ is much looser than those of $D_{\mathrm{Pd}}$ and $D_{\mathrm{Ti}}^{*}$. The curved Arrhenius plots have been explained by the monovacancy mechanism taking into account a temperature dependent migration energy of a vacancy due to the softening of the longitudinal acoustic LA $\frac{2}{3}\langle 111\rangle$ phonon in $\beta$-Ti. It has been recognized that the activation energy estimated for the monovacancy mechanism in the impurity diffusion of $\mathrm{Cr}$ and $\mathrm{Pd}$ and self-diffusion in $\beta$-Ti is proportional to the square of radius of the diffusing atom. This suggests that the size effect is dominant in the impurity diffusion in $\beta$-Ti.
\end{abstract}

(Received February 19, 1991)

Keywords: diffusion of chromium in $\beta$-titanium, diffusion of palladium in $\beta$-titanium, impurity diffusion in $\beta$-titanium, curved Arrhenius plot, size effect on diffusion

\section{Introduction}

To explain the deviation from linearity in the Arrhenius plot of self-diffusion coefficients in the so-called anomalous b.c.c. metals ${ }^{(1)}$, Herzig and Köhler ${ }^{(2)-(4)}$ have recently proposed a model based on the experimental evidence of significant lattice softening of the longitudinal acoustic phonon in $\langle 111\rangle$ direction at reduced wave vector $\frac{2}{3}, \mathrm{LA}_{\frac{2}{3}}\langle 111\rangle$ phonon, in $\beta-\mathrm{Zr}^{(5)}$. According to this model, the free energy of atomic migration $G^{\mathrm{M}}$ in the anomalous b.c.c. metals is expressed by

$$
G^{\mathrm{M}}=G_{0}^{\mathrm{M}}\left(1-T_{0} / T\right),
$$

where $G_{0}^{\mathrm{M}}$ is the free energy of migration of a monovacancy in the monovacancy mechanism, and $T_{0}$ is the hypothetical temperature defined as the lowest temperature for the metal to have the b.c.c. structure. $G^{\mathrm{M}}$ would diminish to zero in the completely softened lattice at $T_{0}$ where the frequency of $\mathrm{LA}^{\frac{2}{3}}\langle 111\rangle$ would diminish to zero. Thus, the temperature dependence of the self-diffusion coefficient, $D$, in the anomalous b.c.c. metals should be expressed by

$$
D=D_{0} \exp (-Q / R T) \exp \left(G_{0}^{\mathrm{M}} T_{0} / R T^{2}\right),
$$

where $D_{0}$ and $Q$ are the frequency factor and the activation energy, respectively, for the monovacancy mechanism in the lattice without the softening. The extent of deviation from the linearity in the Arrhenius plot

* Graduate Student, Tohoku University, Japan. Present address: Department of Ocean Materials Science, Korea Maritime University, Pusan, Republic of Korea.

** Department of Materials Science, Faculty of Engineering, Tohoku University, Aoba, Sendai 980, Japan. of diffusion coefficients is represented by the term exp $\left(G_{0}^{\mathrm{M}} T_{0} / R T^{2}\right)$ in eq. (2). An equation similar to eq. (2) has been obtained by Sanchez and de Fontaine ${ }^{(6)}$ on the basis of the $\omega$ embryo model where the $\omega$ embryo in the transition from the $\beta$ phase to the $\omega$ phase has the same structure as the activated complex, and the $\omega$ embryo is also regarded as a lattice in significantly softened state of LA $\frac{2}{3}\langle 111\rangle$. Herzig and Köhler ${ }^{(4)}$ have shown that eq. (2) holds for the self-diffusion not only in the anomalous b.c.c. metals but also in the normal b.c.c. metals where deviation from linearity in the Arrhenius plot is very slight. Thus, the LA $\frac{2}{3}\langle 111\rangle$ phonon softening model appears to be the most suitable one among the models proposed for the diffusion mechanisms in the b.c.c. metals, so far.

In our previous work on the impurity diffusion of $\mathrm{Cu}$ and $\mathrm{Ag}$ in $\beta$ - $\mathrm{Ti}^{(7)}$, eq. (2) has been confirmed to hold, and it has been recognized that the activation energy estimated for the monovacancy mechanism in the impurity diffusion of $\mathrm{Cu}$ and $\mathrm{Ag}$ and self-diffusion in $\beta$-Ti is proportional to the square of the atomic radius of the diffusing atom. In the present work, to confirm such a size effect for other impurities with different electronic structure from the noble metals, impurity diffusion of transition metals, $\mathrm{Cr}$ and $\mathrm{Pd}$, in $\beta$-Ti has been investigated.

Although impurity diffusion of $\mathrm{Cr}$ in $\beta$-Ti has been studied by the autoradiography ${ }^{(8)(9)}$, the experimental data are insufficient to analyze the temperature dependence of the diffusion coefficients. Impurity diffusion of $\mathrm{Pd}$ in $\beta$-Ti has not been studied, so far.

In the present work, in addition to the new experimental data on diffusion of $\mathrm{Cr}$ and $\mathrm{Pd}$ in $\beta$-Ti, the experimental data on impurity diffusion coefficients of $\mathrm{Sc}^{(10)}, \mathrm{V}^{(11)}$ and $\mathrm{Ta}^{(12)}$ in $\beta$-Ti have been referred to confirm the validity of eq. (2) and to determine the parameters of $D_{0}, Q$ 
and $G_{0}^{M} T_{0}$ in eq. (2). The atomic radii of $\operatorname{Cr}(0.1248 \mathrm{~nm})$, $\mathrm{V}(0.1310 \mathrm{~nm})$ and $\mathrm{Pd}(0.1339 \mathrm{~nm})$ are smaller than that of $\mathrm{Ti}(0.1422 \mathrm{~nm})$, while those of $\mathrm{Ta}(0.1427 \mathrm{~nm})$ and $\mathrm{Sc}(0.1596 \mathrm{~nm})$ are larger than that of $\mathrm{Ti}^{(13)}$, thus it has been possible to examine the size effect for the impurity diffusion in $\beta$-Ti over a wide range of atomic radius of the diffusing atom.

In the present work, interdiffusion experiments with the couples of pure Ti and dilute binary Ti alloys containing $\mathrm{Cr}$ and $\mathrm{Pd}$ have been carried out. Impurity diffusion coefficient of the solute atom in $\beta$-Ti has been determined by extrapolating concentration dependence of the interdiffusion coefficient to the infinite dilution of solute. This method is especially effective in determining impurity diffusion coefficient of the element, such as $\mathrm{Cu}$ and $\mathrm{Pd}$ for which the tracer diffusion experiment with radioactive isotope is not easy.

\section{Experimental Procedure}

Pure Ti rods $12 \mathrm{~mm}$ in diameter and $100 \mathrm{~mm}$ in length were machined from a pure Ti bar $160 \mathrm{~mm}$ in diameter supplied by Kobe Steel Ltd. The main impurities in this material were Fe: $0.046, \mathrm{~N}: 0.0032$ and O: 0.0041 mass $\%$. The rods were polished chemically, then sealed in quartz tubes with high purity argon gas and annealed at $1373 \mathrm{~K}$ for $172.8 \mathrm{ks}(48 \mathrm{~h})$ to cause grain growth. Alumina rings (more than $99 \%$ purity) were fitted up at both ends of the rod to prevent reaction with the quartz tube. The resultant grain size was about $3 \mathrm{~mm}$. The rod was cut to make the disc specimens $5 \mathrm{~mm}$ in thickness. To obtain fully flat surface, the specimen was set in a stainless steel holder $50 \mathrm{~mm}$ in diameter and ground on abrasive paper and polished on a buff with fine alumina paste.

Buttons of $\mathrm{Ti}-4.62$ at $\% \mathrm{Cr}$ and $\mathrm{Ti}-1.84$ at\% $\mathrm{Pd}$ alloys were made by argon arc-melting the pure Ti blocks with Cr flakes of $99.4 \%$ purity and Pd plates of $99.7 \%$ purity. To homogenize the buttons, the arc-melting was repeated a few times. Finally, the buttons were cast into a copper boat water-cooled to make an ingot $10 \mathrm{~mm}$ in diameter and $80 \mathrm{~mm}$ in length. The resultant grain size after the same grain growth treatment as described above was about $2 \mathrm{~mm}$. The alloy rods were cut to make disc specimens $5 \mathrm{~mm}$ in thickness. The cut surface of the alloy specimen was ground and polished in the same way as the pure Ti specimen.

To make the semi-infinite interdiffusion couple the pure $\mathrm{Ti}$ and the alloy discs were put in a stainless steel holder with two screws, pressed by the screws and wrapped by a vanadium foil and surrounded by titanium sponges, and then diffusion-welded by heating at $1073 \mathrm{~K}$ for $3.6 \mathrm{ks}$ in a stream of high purity argon gas. After the diffusion-welding, the couple was removed from the holder and put into an alumina tube with high purity argon gas. By putting the quartz tube in a furnace, diffusion annealing was carried out at temperatures in the range from 1173 to $1823 \mathrm{~K}$ for $2.4 \mathrm{ks}$ to $2.16 \mathrm{Ms}$. For diffusion above $1673 \mathrm{~K}$, the couple was sealed in double tubes of quartz, keeping the inner tube from crushing by adjusting the pressure of argon gas between the inner and outer tubes. The diffusion temperature was controlled within $\pm 1 \mathrm{~K}$ at $1173-1473 \mathrm{~K}$ and $\pm 3 \mathrm{~K}$ at $1673-1823 \mathrm{~K}$.

After the diffusion, the couple was cut parallel to the diffusion direction, and the cut surfaces were polished on a buff with fine alumina paste to examine the concentration-penetration profiles by an electron probe microanalyzer (Shimadzu ARL-II), operated under the conditions; accelerating voltage, $20 \mathrm{kV}$; take-off angle of $\mathrm{Cr}-K \alpha$ and $\mathrm{Pd}-L \alpha \mathrm{X}$-rays, $0.916 \mathrm{rad}$; specimen current, $50 \mathrm{nA}$; line scanning speed, $100 \mu \mathrm{m} / \mathrm{min}$. In the case of $\mathrm{Ti}-\mathrm{Cr}$ system, the calibration curve was obtained by the aid of the standard specimens for which chemical analyses were carried out. It showed that the relative intensity of $\mathrm{Cr}-K \alpha \mathrm{X}$-ray emitted from the specimen was proportional to the mole fraction of $\mathrm{Cr}$. In the case of the Ti-Pd system for which the concentration of $\mathrm{Pd}$ in the present work was low, it could be reasonably assumed that the relative intensity of $\mathrm{Pd}-L \alpha \mathrm{X}$-ray was proportional to the mole fraction of $\mathrm{Pd}$. This was confirmed with the calculation by Philibert's method ${ }^{(14)}$ and Pool and Thomas's method ${ }^{(15)}$. The interdiffusion coefficient was determined as a function of solute concentration by Matano's method ${ }^{(16)}$. The molar volume of $\mathrm{Ti}-\mathrm{Cr}$ alloys ${ }^{(17)}$ has been shown to be proportional to the mole fraction of $\mathrm{Cr}$, indicating that both the partial molar volumes of $\mathrm{Cr}$ and $\mathrm{Ti}$ are independent of concentration of $\mathrm{Cr}$. The experimental data on the molar volume of $\mathrm{Ti}-\mathrm{Pd}$ alloys are not available, but it may be reasonable to assume that the partial molar volumes of $\mathrm{Pd}$ and $\mathrm{Ti}$ are constant because of the diluteness of the $\mathrm{Ti}-\mathrm{Pd}$ alloys studied in the present work. Therefore, the mole of solute $(\mathrm{Cr}$ and $\mathrm{Pd}$ ) per cubic meter could be used as the unit of concentration in the analysis of diffusion.

\section{Results and Discussion}

Figure 1 shows the concentration dependence of the interdiffusion coefficient, $\tilde{D}$, in $\mathrm{Ti}-\mathrm{Cr}$ alloys determined with (pure Ti)-(Ti-4.62 at\% Cr alloy) couples in the temperature range between 1173 and $1823 \mathrm{~K}$. Interdiffusion coefficients determined for different diffusion times are shown distinguishably from each other by different marks $(\bigcirc, \bullet$ and $\triangle$ ). As shown in Fig. 1, at each temperature $\tilde{D}$ is independent of diffusion time. According to Darken's relation $^{(18)}$, the extrapolated value of $\tilde{D}$ to the infinite dilution of $\mathrm{Cr}$ can be regarded as the impurity diffusion coefficient of $\mathrm{Cr}, D_{\mathrm{Cr}}$, in $\beta$-Ti. The values of $D_{\mathrm{Cr}}$ determined in this way are listed in Table 1 with the marks corresponding to those in Fig. 1. If the impurity diffusion coefficient is perfectly independent of concentration of solute, it can be also determined from the slope of a straight line in the plot of probability function of concentration of solute versus distance ${ }^{(19)}$. However, the plot of the present data does not show a fully single straight line. This may be due to slight dependence of $\tilde{D}$ on concentration of solute. Then, in the present work Matano's method has been employed to determine the interdiffu- 
Table 1 Impurity diffusion coefficient of $\mathrm{Cr}$ in $\beta$-Ti.

\begin{tabular}{|c|c|c|c|}
\hline $\begin{array}{c}\text { Diffusion } \\
\text { temperature } \\
T / \mathrm{K}\end{array}$ & $\begin{array}{c}\text { Diffusion } \\
\text { time } \\
t / s\end{array}$ & $\begin{array}{l}\text { Diffusion } \\
\text { coefficient } \\
D_{\mathrm{Cr}} / \mathrm{m}^{2} \mathrm{~s}^{-1}\end{array}$ & Mark \\
\hline 1823 & $2.40 \times 10^{3}$ & $(3.44 \pm 0.21) \times 10^{-11}$ & 0 \\
\hline 1773 & $3.60 \times 10^{3}$ & $(2.48 \pm 0.14) \times 10^{-11}$ & 0 \\
\hline 1723 & $5.40 \times 10^{3}$ & $(1.74 \pm 0.11) \times 10^{-11}$ & 0 \\
\hline \multirow[t]{2}{*}{1673} & $7.20 \times 10^{3}$ & $(1.33 \pm 0.11) \times 10^{-11}$ & 0 \\
\hline & $1.08 \times 10^{4}$ & $(1.35 \pm 0.07) \times 10^{-11}$ & - \\
\hline \multirow[t]{2}{*}{1623} & $9.00 \times 10^{3}$ & $(9.01 \pm 0.47) \times 10^{-12}$ & 0 \\
\hline & $1.44 \times 10^{4}$ & $(9.31 \pm 0.91) \times 10^{-12}$ & $\bullet$ \\
\hline \multirow[t]{3}{*}{1573} & $1.44 \times 10^{4}$ & $(5.99 \pm 0.24) \times 10^{-12}$ & 0 \\
\hline & $2.16 \times 10^{4}$ & $(5.94 \pm 0.28) \times 10^{-12}$ & $\bullet$ \\
\hline & $2.88 \times 10^{4}$ & $(6.00 \pm 0.37) \times 10^{-12}$ & $\triangle$ \\
\hline \multirow[t]{2}{*}{1523} & $2.88 \times 10^{4}$ & $(4.24 \pm 0.27) \times 10^{-12}$ & 0 \\
\hline & $4.32 \times 10^{4}$ & $(4.18 \pm 0.27) \times 10^{-12}$ & - \\
\hline \multirow[t]{3}{*}{1473} & $2.88 \times 10^{4}$ & $(2.66 \pm 0.13) \times 10^{-12}$ & 0 \\
\hline & $4.32 \times 10^{4}$ & $(2.67 \pm 0.21) \times 10^{-12}$ & - \\
\hline & $6.48 \times 10^{4}$ & $(2.51 \pm 0.04) \times 10^{-12}$ & $\triangle$ \\
\hline \multirow[t]{2}{*}{1423} & $4.32 \times 10^{4}$ & $(1.74 \pm 0.12) \times 10^{-12}$ & 0 \\
\hline & $7.92 \times 10^{4}$ & $(1.73 \pm 0.09) \times 10^{-12}$ & - \\
\hline \multirow[t]{3}{*}{1373} & $2.16 \times 10^{4}$ & $(1.05 \pm 0.08) \times 10^{-12}$ & 0 \\
\hline & $4.32 \times 10^{4}$ & $(1.08 \pm 0.06) \times 10^{-12}$ & $\bullet$ \\
\hline & $8.64 \times 10^{4}$ & $(1.03 \pm 0.06) \times 10^{-12}$ & $\triangle$ \\
\hline \multirow[t]{2}{*}{1323} & $1.73 \times 10^{5}$ & $(6.44 \pm 0.35) \times 10^{-13}$ & 0 \\
\hline & $2.59 \times 10^{5}$ & $(6.28 \pm 0.44) \times 10^{-13}$ & $\bullet$ \\
\hline \multirow[t]{2}{*}{1273} & $1.73 \times 10^{5}$ & $(3.69 \pm 0.28) \times 10^{-13}$ & 0 \\
\hline & $2.59 \times 10^{5}$ & $(3.48 \pm 0.21) \times 10^{-13}$ & - \\
\hline 1223 & $6.91 \times 10^{5}$ & $(2.04 \pm 0.15) \times 10^{-13}$ & 0 \\
\hline \multirow[t]{2}{*}{1173} & $4.32 \times 10^{5}$ & $(1.16 \pm 0.07) \times 10^{-13}$ & 0 \\
\hline & $6.91 \times 10^{5}$ & $(1.10 \pm 0.08) \times 10^{-13}$ & $\bullet$ \\
\hline
\end{tabular}

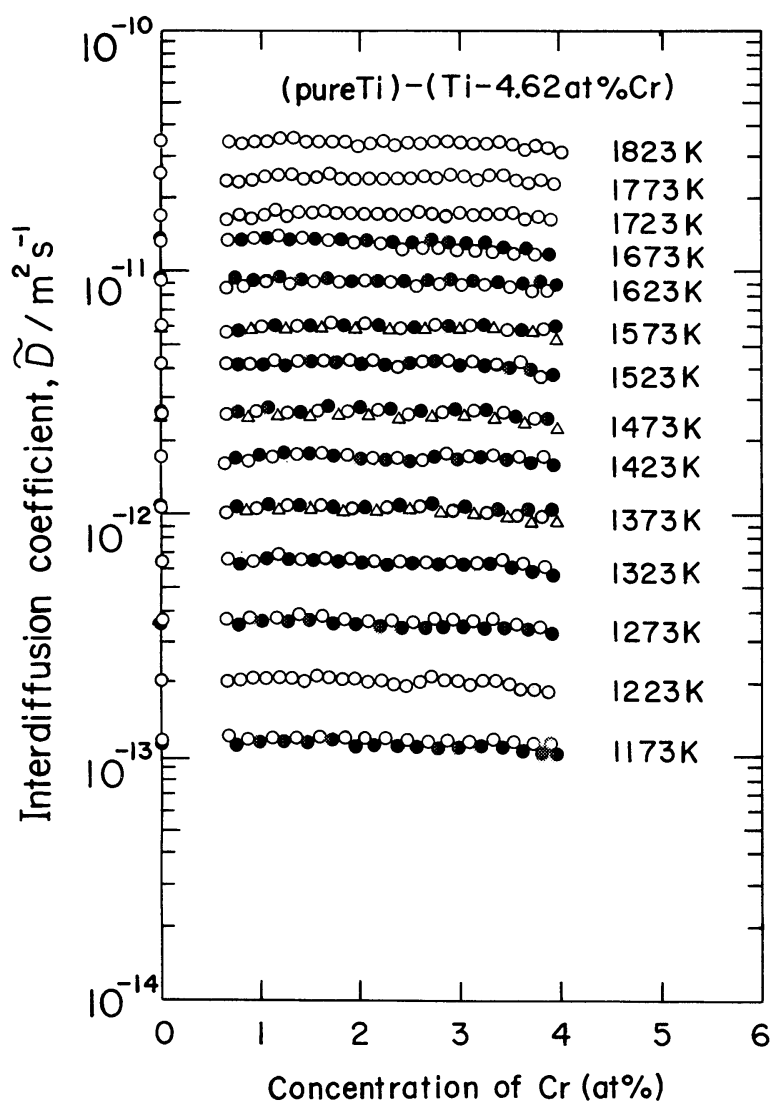

Fig. 1 Concentration dependence of interdiffusion coefficient $\tilde{D}$ in $\mathrm{Ti}-\mathrm{Cr}$ alloys. sion coefficient as a function of concentration of solute.

Figure 2 shows the concentration dependence of the interdiffusion coefficient $\tilde{D}$ in Ti-Pd alloys determined with (pure Ti)-(Ti-1.84 at\% Pd alloy) couples in the temperature range between 1173 and $1823 \mathrm{~K}$. Also in this alloy, $\tilde{D}$ is recognized to be independent of diffusion time. The impurity diffusion coefficients of $\mathrm{Pd}, D_{\mathrm{Pd}}$, in $\beta$-Ti determined in the same way as $D_{\mathrm{Cr}}$ are listed in Table 2 with marks corresponding to those in Fig. 2.

Figure 3 shows the temperature dependence of $D_{\mathrm{Cr}}$ and $D_{\text {Pd }}$ in $\beta$-Ti determined by the present experiments, in comparison with that of the tracer diffusion coefficient of $\mathrm{Cr}, D_{\mathrm{Cr}}^{*}$, in $\beta$-Ti determined by Mortlock and Tomlin ${ }^{(8)}$ and that of the tracer selfdiffusion coefficient $D_{\mathrm{Ti}}^{*}$ by Köhler and Herzig ${ }^{(3)}$. The magnitude of $D_{\mathrm{Cr}}$ is nearly equal to that of $D_{\mathrm{Cr}}^{*}$, as predicted by Darken's relation ${ }^{(18)}$. In the whole temperature range of $\beta-\mathrm{Ti}, D_{\mathrm{Cr}}$ is about twice as large as $D_{\mathrm{Ti}}^{*}$. On the other hand, the magnitude of $D_{\mathrm{Pd}}$ lies in the range between $D_{\mathrm{Cr}}$ and $D_{\mathrm{Ti}}^{*}$, that is, at higher temperatures $D_{\mathrm{Pd}}$ is nearly of the same magnitude as $D_{\mathrm{Cr}}$ and at lower temperatures the magnitude of $D_{\mathrm{Pd}}$ is nearly equal to that of $D_{\mathrm{Ti}}^{*}$. In the Arrhenius plot of $D_{\mathrm{Cr}}$ and $D_{\mathrm{Pd}}$ an upward curvature is recognized as in the case of $D_{\mathrm{Ti}}^{*}$, but the curvature of the plot of $D_{\mathrm{Cr}}$ is much looser than those of $D_{\mathrm{Pd}}$ and $D_{\mathrm{Ti}}^{*}$. Fitting the experimental values of $D_{\mathrm{Cr}}$ and $D_{\mathrm{Pd}}$ into eq. (2), the parameters, $D_{0}, Q$ and $G_{0}^{\mathrm{M}} T_{0}$, and the probable errors are calculated as listed in Table 3 together with those for $\mathrm{Cu}$ and $\mathrm{Ag}$ calculated

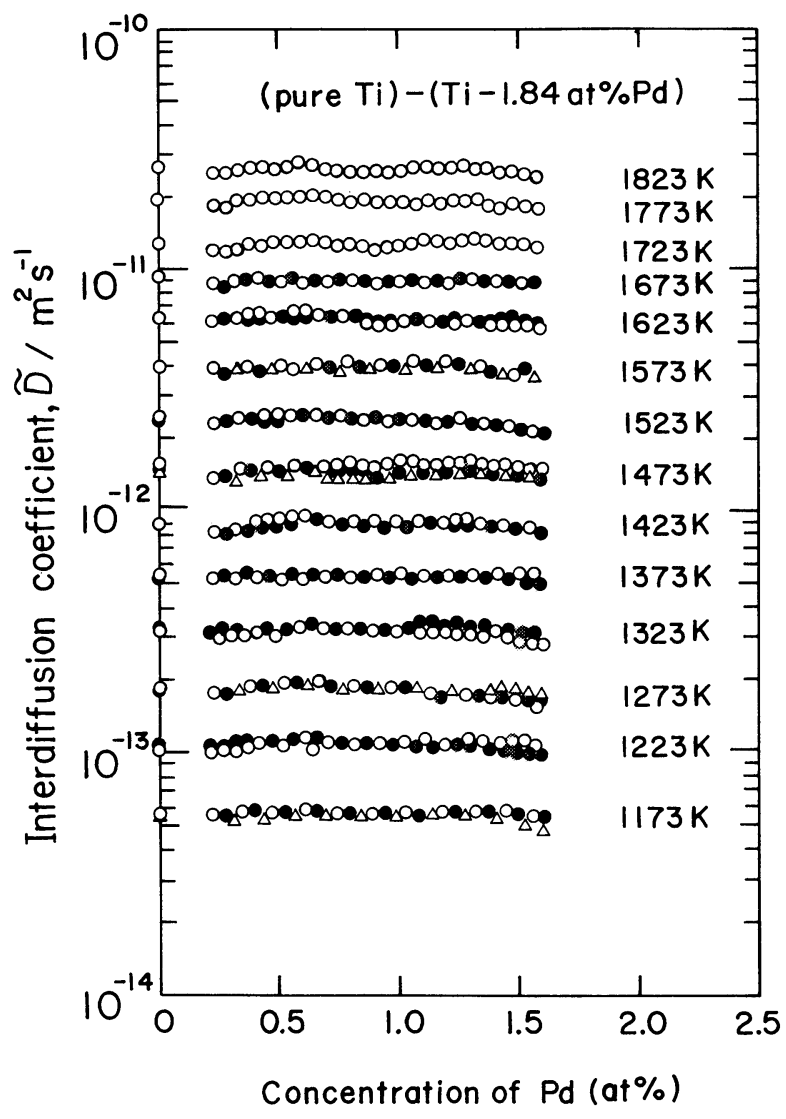

Fig. 2 Concentration dependence of interdiffusion coefficient $\tilde{D}$ in Ti-Pd alloys. 
Table 2 Impurity diffusion coefficient of $\mathrm{Pd}$ in $\beta$-Ti.

\begin{tabular}{|c|c|c|c|}
\hline $\begin{array}{c}\text { Diffusion } \\
\text { temperature } \\
T / \mathrm{K}\end{array}$ & $\begin{array}{c}\text { Diffusion } \\
\text { time } \\
t / \mathrm{s}\end{array}$ & $\begin{array}{l}\text { Diffusion } \\
\text { coefficient } \\
D_{\mathrm{Pd}} / \mathrm{m}^{2} \mathrm{~s}^{-1}\end{array}$ & Mark \\
\hline 1823 & $2.40 \times 10^{3}$ & $(2.59 \pm 0.07) \times 10^{-11}$ & 0 \\
\hline 1773 & $3.60 \times 10^{3}$ & $(1.94 \pm 0.12) \times 10^{-11}$ & 0 \\
\hline 1723 & $5.40 \times 10^{3}$ & $(1.26 \pm 0.06) \times 10^{-11}$ & 0 \\
\hline \multirow[t]{2}{*}{1673} & $7.20 \times 10^{3}$ & $(9.00 \pm 0.51) \times 10^{-12}$ & O \\
\hline & $1.08 \times 10^{4}$ & $(9.06 \pm 0.29) \times 10^{-12}$ & - \\
\hline \multirow[t]{2}{*}{1623} & $9.00 \times 10^{3}$ & $(6.11 \pm 0.43) \times 10^{-12}$ & 0 \\
\hline & $1.44 \times 10^{4}$ & $(6.22 \pm 0.49) \times 10^{-12}$ & - \\
\hline \multirow[t]{3}{*}{1573} & $1.44 \times 10^{4}$ & $(3.89 \pm 0.27) \times 10^{-12}$ & 0 \\
\hline & $2.16 \times 10^{4}$ & $(3.82 \pm 0.39) \times 10^{-12}$ & $\bullet$ \\
\hline & $2.88 \times 10^{4}$ & $(3.89 \pm 0.29) \times 10^{-12}$ & $\triangle$ \\
\hline \multirow[t]{2}{*}{1523} & $3.78 \times 10^{4}$ & $(2.40 \pm 0.12) \times 10^{-12}$ & $\overline{0}$ \\
\hline & $6.48 \times 10^{4}$ & $(2.38 \pm 0.15) \times 10^{-12}$ & $\bullet$ \\
\hline \multirow[t]{3}{*}{1473} & $2.88 \times 10^{4}$ & $(1.49 \pm 0.11) \times 10^{m-12}$ & 0 \\
\hline & $5.76 \times 10^{4}$ & $(1.41 \pm 0.08) \times 10^{-12}$ & $\bullet$ \\
\hline & $8.64 \times 10^{4}$ & $(1.38 \pm 0.10) \times 10^{-12}$ & $\triangle$ \\
\hline \multirow[t]{2}{*}{1423} & $8.64 \times 10^{4}$ & $(8.96 \pm 0.37) \times 10^{-13}$ & 0 \\
\hline & $1.44 \times 10^{5}$ & $(8.58 \pm 0.33) \times 10^{-13}$ & $\bullet$ \\
\hline \multirow[t]{2}{*}{1373} & $8.64 \times 10^{4}$ & $(5.32 \pm 0.29) \times 10^{-13}$ & 0 \\
\hline & $5.18 \times 10^{5}$ & $(5.27 \pm 0.27) \times 10^{-13}$ & $\bullet$ \\
\hline \multirow[t]{2}{*}{1323} & $4.32 \times 10^{5}$ & $(3.10 \pm 0.17) \times 10^{-13}$ & 0 \\
\hline & $6.91 \times 10^{5}$ & $(3.16 \pm 0.24) \times 10^{-13}$ & $\bullet$ \\
\hline \multirow[t]{3}{*}{1273} & $6.05 \times 10^{5}$ & $(1.77 \pm 0.11) \times 10^{-13}$ & 0 \\
\hline & $9.50 \times 10^{5}$ & $(1.80 \pm 0.13) \times 10^{-13}$ & $\bullet$ \\
\hline & $1.30 \times 10^{6}$ & $(1.82 \pm 0.10) \times 10^{-13}$ & $\triangle$ \\
\hline \multirow[t]{2}{*}{1223} & $8.64 \times 10^{5}$ & $(1.07 \pm 0.08) \times 10^{-13}$ & 0 \\
\hline & $1.47 \times 10^{6}$ & $(1.07 \pm 0.10) \times 10^{-13}$ & $\bullet$ \\
\hline \multirow[t]{3}{*}{1173} & $8.64 \times 10^{5}$ & $(5.63 \pm 0.23) \times 10^{-14}$ & O \\
\hline & $1.47 \times 10^{6}$ & $(5.55 \pm 0.37) \times 10^{-14}$ & $\bullet$ \\
\hline & $2.16 \times 10^{6}$ & $(5.38 \pm 0.21) \times 10^{-14}$ & $\triangle$ \\
\hline
\end{tabular}

previously by the present authors ${ }^{(7)}$.

Temperature dependence of the impurity diffusion coefficients of $\mathrm{Sc}^{(10)}, \mathrm{V}^{(11)}$ and $\mathrm{Ta}^{(12)}$ in $\beta$-Ti is shown in Fig. 4 in comparison with that of self-diffusion ${ }^{(3)}$ in $\beta$-Ti. Here, it is recognized that $D_{\mathrm{Sc}}^{*}>D_{\mathrm{V}}^{*} \approx D_{\mathrm{Ii}}^{*}>D_{\mathrm{Ta}}^{*}$. The parameters of $D_{0}, Q$ and $G_{0}^{\mathrm{M}} T_{0}$ for diffusion of Sc, $\mathrm{V}$ and $\mathrm{Ta}$ in $\beta$-Ti are also calculated and listed in Table 3.

If eq. (2) is applicable, the softening of $\mathrm{LA}_{3}^{2}\langle 111\rangle$ phonon increases the diffusion coefficient $D$ by the factor $\exp \left(G_{0}^{\mathrm{M}} T_{0} / R T^{2}\right)$. In Table 3, values of this factor at the melting temperature of $\mathrm{Ti}\left(T_{\mathrm{m}}=1943 \mathrm{~K}\right)$ and at the $\beta-\alpha$ transformation temperature of $\mathrm{Ti}\left(T_{\beta-\alpha}=1155 \mathrm{~K}\right)$ are also listed for the impurity diffusion of the seven elements in $\beta$-Ti and the self-diffusion in $\beta$-Ti. At $T_{\mathrm{m}}$, the factor ranges from 3.2 to 92 , depending on the diffusing

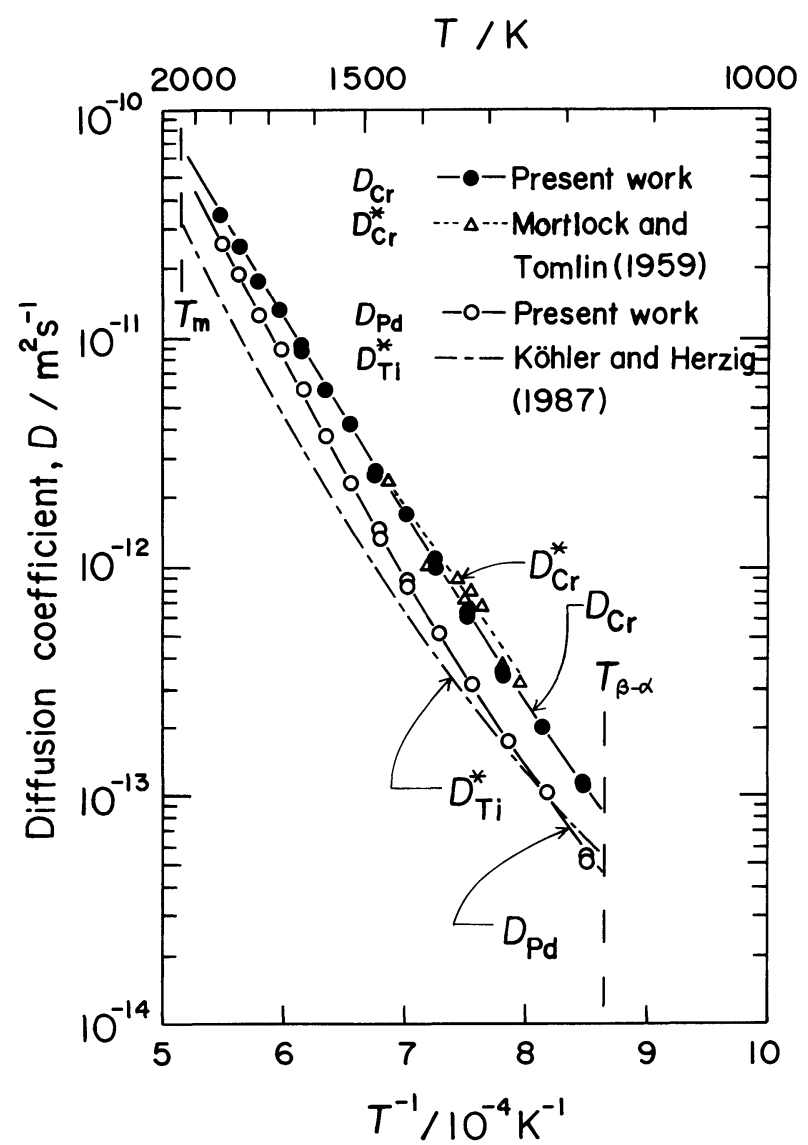

Fig. 3 Temperature dependence of diffusion coefficients of $\mathrm{Cr}$ and $\mathrm{Pd}$ in $\beta$-Ti.

element, however, at $T_{\beta-\alpha}$ it ranges much more widely, from 27 to $3.6 \times 10^{5}$.

Since $Q$ is the sum of enthalpy of the formation $H_{0}^{\mathrm{F}}$ and the migration $H_{0}^{\mathrm{M}}$ of a monovacancy, $G_{0}^{\mathrm{M}} T_{0}$ can be written as

$$
\begin{aligned}
G_{0}^{\mathrm{M}} T_{0} & =\left(H_{0}^{\mathrm{M}}-T S_{0}^{\mathrm{M}}\right) T_{0} \\
& =\left(Q-H_{0}^{\mathrm{F}}\right) T_{0}-T_{0} S_{0}^{\mathrm{M}} T,
\end{aligned}
$$

where $S_{0}^{\mathrm{M}}$ is the entropy of migration of a monovacancy. According to Sanchez ${ }^{(20)}$, the term $T_{0} S_{0}^{\mathrm{M}}$ is negligible compared with $H_{0}^{\mathrm{M}}\left(=Q-H_{0}^{\mathrm{F}}\right)$. Because we are concerned with $\beta$-Ti, $T_{\beta-\alpha}(=1155 \mathrm{~K})<T<T_{\mathrm{m}}(=1943 \mathrm{~K})$, and $T_{0}$ is $657 \mathrm{~K}$, as estimated below. Thus, the second term of the right hand side in eq. (3) is much smaller than the first

\begin{tabular}{|c|c|c|c|c|c|c|}
\hline & $D_{0} / \mathrm{m}^{2} \mathrm{~s}^{-1}$ & $Q / \mathrm{kJmol}^{-1}$ & $G_{0}^{\mathrm{M}} T_{0} / \mathrm{MJmol}^{-1} \mathrm{~K}$ & $\exp \left(\frac{G_{0}^{\mathrm{M}} T_{0}}{R T_{\mathrm{m}}^{2}}\right)$ & $\exp \left(\frac{G_{0}^{\mathrm{M}} T_{0}}{R T_{\beta-\alpha}^{2}}\right)$ & $r / 10^{-10} \mathrm{~m}$ \\
\hline $\mathrm{Ti} \rightarrow \mathrm{Ti}$ & $3.5 \times 10^{-4}$ & $328 \pm 25$ & $129 \pm 18$ & 61 & $1.1 \times 10^{5}$ & 1.422 \\
\hline $\mathrm{Pd} \rightarrow \mathrm{Ti}$ & $\left(5.70_{-2.16}^{+3.47}\right) \times 10^{-4}$ & $310 \pm 11$ & $99.7 \pm 7.9$ & 24 & $8.0 \times 10^{3}$ & 1.339 \\
\hline $\mathrm{Sc} \rightarrow \mathrm{Ti}$ & $\left(2.46_{-2.38}^{+7.00}\right) \times 10^{-4}$ & $298 \pm 77$ & $108 \pm 52$ & 31 & $1.7 \times 10^{4}$ & 1.596 \\
\hline $\mathrm{V} \rightarrow \mathrm{Ti}$ & $\left(3.17_{-1.95}^{+5.07}\right) \times 10^{-3}$ & $352 \pm 23$ & $124 \pm 17$ & 52 & $7.2 \times 10^{4}$ & 1.310 \\
\hline $\mathrm{Cu} \rightarrow \mathrm{Ti}$ & $\left(5.70_{-1.66}^{+2.34}\right) \times 10^{-5}$ & $241 \pm 8$ & $72.6 \pm 5.6$ & 10 & $7.0 \times 10^{2}$ & 1.244 \\
\hline $\mathrm{Ag} \rightarrow \mathrm{Ti}$ & $\left(1.08_{-0.58}^{+1.25}\right) \times 10^{-3}$ & $353 \pm 18$ & $142 \pm 13$ & 92 & $3.6 \times 10^{5}$ & 1.406 \\
\hline
\end{tabular}

Table 3 Parameters for the anomalous diffusion in $\beta$-Ti. 


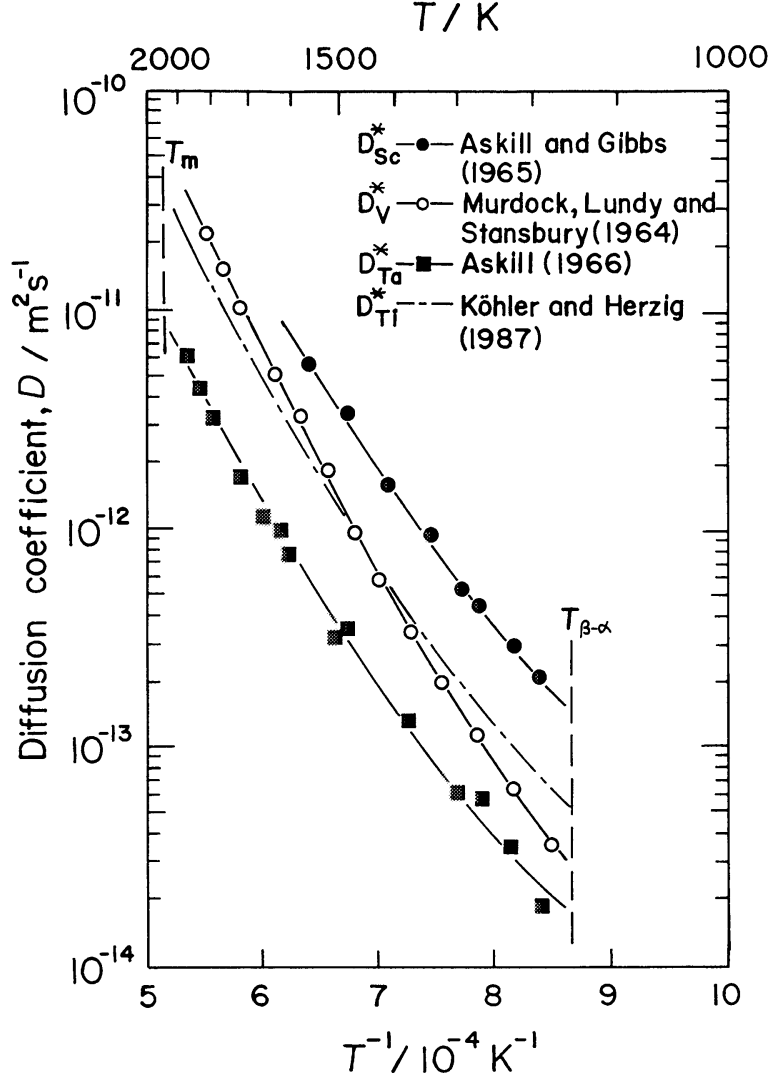

Fig. 4 Temperature dependence of diffusion coefficients of Sc, V and $\mathrm{Ta}$ in $\beta$-Ti

term. Then $G_{0}^{\mathrm{M}} T_{0}$ increases in proportion to $T_{0}$ with increasing activation energy $Q$. This is confirmed by the present and previous experimental results ${ }^{(7)(10)-(12)}$, as shown in Fig. 5, where for diffusion of all the eight elements in $\beta$ - $\mathrm{Ti}$, a single straight line can be drawn, indicating that $H_{0}^{\mathrm{F}}$ is constant independent of the element. The value of $H_{0}^{\mathrm{F}}$ is estimated to be $142 \mathrm{kJmol}^{-1}$ by extrapolating $Q$ to $G_{0}^{\mathrm{M}} T_{0}=0$ in Fig. 5. From the slope of the straight line in Fig. 5, $T_{0}$ is estimated to be $657 \mathrm{~K}$. This means that the activation energy $Q$ for the impurity diffusion in $\beta$-Ti is controlled by the value of $H_{0}^{\mathrm{M}}$ rather than $H_{0}^{\mathrm{F}}$.

According to Sanchez and de Fontaine ${ }^{(6)}$, the free energy of formation of the $\omega$ embryo (or the activated complex), $G_{\omega}$, is correlated with the transforming parameter from the $\beta$ phase to the $\omega$ phase, $\varepsilon$, by

$$
G_{\omega}=A(T, p) \varepsilon^{2}-B(T, p) \varepsilon^{3},
$$

where $A(T, p)$ and $B(T, p)$ are the functions of both temperature, $T$, and pressure, $p . \varepsilon$ is proportional to the atomic displacement in the $\beta$ phase lattice which participates in the formation of the $\omega$ embryo $^{(21)} \cdot \varepsilon=0$ in the perfect b.c.c. structure, but $\varepsilon=1$ in the perfectly transformed lattice ( $\omega$ phase). The driving force for the transformation expressed by the second term $B(T, p) \varepsilon^{3}$ is negligible at higher temperatures but increases with decreasing temperature. On the other hand, in the temperature range much higher than $T_{\omega}$, which is the highest temperature for the $\omega$ phase to exist, only the first term

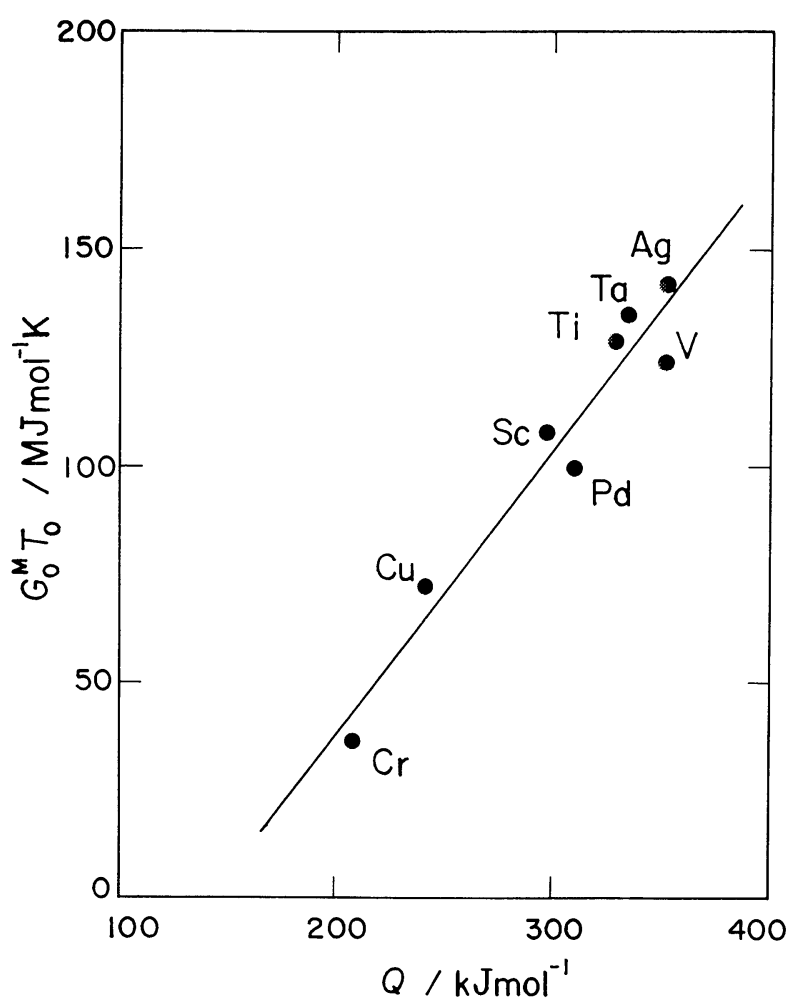

Fig. 5 Plot of $G_{0}^{\mathrm{M}} T_{0}$ versus $Q$ for diffusion in $\beta$-Ti. $G_{0}^{\mathrm{M}}$ : the free energy of migration of a monovacancy, $T_{0}$ : the hypothetical temperature defined as the lowest temperature for the metal to have the b.c.c. structure, $Q$ : activation energy estimated for diffusion via the monovacancy mechanism.

$A(T, p) \varepsilon^{2}$ is significant, and the normal monovacancy mechanism operates for the diffusion, then

$$
G_{\omega}\left(T \gg T_{\omega}\right) \simeq A \varepsilon^{2}=G_{0}^{\mathrm{M}}=H_{0}^{\mathrm{M}}-T S_{0}^{\mathrm{M}} .
$$

By the theoretical considerations ${ }^{(20)}$, it has been supposed that $T_{\beta-\alpha}>T_{\omega}>T_{0}$. In the process of formation of the $\omega$ phase of the h.c.p. structure from b.c.c. $\beta$-Ti by the lattice displacement in the $\langle 111\rangle$ direction, the intrinsic strain due to an activated configuration contributing to the transformation to the $\omega$ phase comes about $3.4 \%$ in the direction [1 $\overline{2} 1$ ] in the $\beta$ phase. However, if the atomic radius of one of the two atoms located on the unit cell of the $\omega$ phase is larger by $1.7 \%$ than that of the other atom, the intrinsic strain in the $\omega$ phase must be just canceled out, and the value of $\varepsilon$ becomes unity. Furthermore, in the activated configuration the frequency of $\mathrm{LA} \frac{2}{3}\langle 111\rangle$ is zero and the b.c.c. structure becomes completely unstable, thus the migration energy of an activated atom to the nearest neighbor vacancy becomes to be maximum. If the radius of diffusing impurity atom $r$ is smaller than 1.017 times the radius of solvent atom $r_{\mathrm{m}}$, the parameter $\varepsilon$ can be represented by

$$
\varepsilon=r / 1.017 r_{\mathrm{m}} \quad\left(r \leqq 1.017 r_{\mathrm{m}}\right)
$$

and for the impurity atom larger than $1.017 r_{\mathrm{m}}$

$$
\varepsilon=1-\left(r-1.017 r_{\mathrm{m}}\right) / 1.017 r_{\mathrm{m}} \quad\left(r \geqq 1.017 r_{\mathrm{m}}\right) .
$$

From eqs. (5) (7), it can be concluded that the migration enthalpy of an impurity in the direction [121] is pro- 


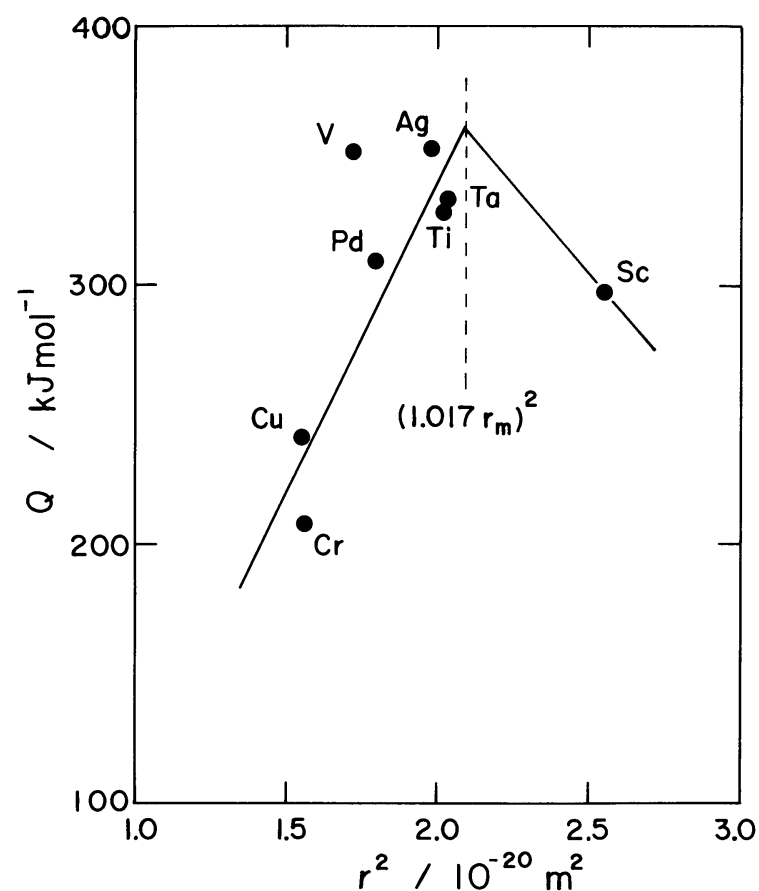

Fig. 6 Plot of the activation energy $Q$ estimated for diffusion via the monovacancy mechanism versus the square of radius $r^{2}$ of diffusing atom in $\beta$-Ti.

portional to the square of the radius of the impurity atom. As the coordination number in the b.c.c. structure of the $\beta$-Ti is eight, the atomic radius of the metal of different structure from the b.c.c. is converted for the coordination number eight by the conversion relation ${ }^{(13)}$ and shown in the last column of Table 3. As shown in Fig. 6, for $r<1.017 r_{\mathrm{m}}, Q$ increases linearly with increasing $r^{2}$, and for $1.017 r_{\mathrm{m}}<r, Q$ decreases with increasing $r^{2}$. This is consistent with the prediction that $H_{0}^{\mathrm{M}}\left(=Q-H_{0}^{\mathrm{F}}\right)$ is proportional to $r^{2}$, as deduced from eqs. (5)-(7). Thus, it must be emphasized that the size effect is dominant in the impurity diffusion in $\beta$-Ti.

\section{Conclusions}

The present experimental results show that the Arrhenius plots of the impurity diffusion coefficients of $\mathrm{Cr}$ and $\mathrm{Pd}$ in $\beta$-Ti in the temperature range 1173 to $1823 \mathrm{~K}$ exhibit an upward curvature. This can be explained by a monovacancy mechanism with a temperature dependent migration energy due to the softening of the $\mathrm{LA} \frac{2}{3}\langle 111\rangle$ phonon in $\beta$-Ti. The activation energy estimated for the monovacancy mechanism in the impurity diffusion of $\mathrm{Cr}$ and $\mathrm{Pd}$ and the self-diffusion in $\beta$-Ti is proportional to the square of radius of the impurity atom.

\section{Acknowledgments}

This work was supported by the Grant-in-Aid for Scientific Research (62420044) from the Ministry of Education, Science and Culture. The authors are indebted to Dr. Y. Shugo (Research Institute of Mineral Dressing and Metallurgy, Tohoku University, now at Daido Steel Co. Ltd.) for his help in arc-melting of the alloys. The authors wish to thank Kobe Steel Ltd. for supply of pure Ti rods. One of the authors (S.-Y. L.) expresses his appreciation to the Ministry of Education, Science and Culture of Japan and to Tohoku University for a scholarship during his doctorate work at Tohoku University.

\section{REFERENCES}

(1) A. D. LeClaire: Diffusion in Body Centred Cubic Metals, ASM, Metals Park, Ohio, (1965) p. 3.

(2) Ch. Herzig and U. Köhler: Mater. Sci. Forum, 15-18 (1987), 301.

(3) U. Köhler and Ch. Herzig: Phys. Status Solidi (b), 144 (1987), 243.

(4) U. Köhler and Ch. Herzig: Phil. Mag. A, 58 (1988), 769.

(5) C. Stassis, J. Zarestky and N. Wakabayashi: Phys. Rev. Lett., 41 (1978), 1726.

(6) J. M. Sanchez and D. de Fontaine: Phys. Rev. Lett., 35 (1975), 227.

(7) S.-Y. Lee, Y. Iijima and K. Hirano: J. Japan Inst. Metals, 54 (1990), 502.

(8) A. J. Mortlock and D. H. Tomlin: Phil. Mag., 4 (1959), 628.

(9) G. B. Gibbs, D. Graham and D. H. Tomlin: Phil. Mag., 8 (1963), 1269.

(10) J. Askill and G. B. Gibbs: Phys. Status Solidi, 11 (1965),557.

(11) J. F. Murdock, T. S. Lundy and E. E. Stansbury: Acta Met., 12 (1964), 1033.

(12) J. Askill: Phys. Status Solidi, 16 (1966), K63.

(13) W. B. Pearson: The Crystal Chemistry and Physics of Metals and Alloys, John Wiley \& Sons, Inc., New York, (1972), p. 135.

(14) J. Philibert: Proc. 3rd Inter. Symp. X-ray Optics and X-ray Microanalysis, Academic Press, New York, (1962) p. 379.

(15) D. M. Poole and P. M. Thomas: J. Inst. Metals, 90 (1962), 228.

(16) C. Matano: Japan J. Phys., 8 (1933), 109.

(17) J. L. Murray: Bulletin Alloy Phase Diagrams, 2 (1981), 174.

(18) L. S. Darken: Trans. AIME, 175 (1948), 148.

(19) P. G. Shewmon: Diffusion in Solids, McGraw-Hill Book Company, Inc., New York, (1963), p.11.

(20) J. M. Sanchez: Phil. Mag. A, 43 (1981), 1407.

(21) H. E. Cook: Acta Met., 21 (1973), 1431. 